\title{
Prediction of Adherence to a 9-Week Corporate Wellness Walking Program
}

\author{
Megan Flynn1, Eric E. Hall2* \\ ${ }^{1}$ Department of Public Health Studies, Elon University, Elon, NC, USA \\ ${ }^{2}$ Department of Exercise Science, Elon University, Elon, NC, USA \\ Email: *ehall@elon.edu
}

How to cite this paper: Flynn, M. and Hall, E.E. (2018) Prediction of Adherence to a 9-Week Corporate Wellness Walking Program. Health, 10, 1734-1748.

https://doi.org/10.4236/health.2018.1012131

Received: October 22, 2018

Accepted: December 18, 2018

Published: December 21, 2018

Copyright $\odot 2018$ by authors and Scientific Research Publishing Inc. This work is licensed under the Creative Commons Attribution International License (CC BY 4.0).

http://creativecommons.org/licenses/by/4.0/

\begin{abstract}
The health and economic benefits of workplace wellness programs are well founded, but the favorable results only occur when employees choose to participate and adhere to these programs. The objective of this study was to use the Theory of Planned Behavior and Self-Efficacy Theory to predict whether participants adhered to a corporate wellness walking program. The sample consisted of 110 faculty and staff at a private university who enrolled in a walking program through the university's wellness center. Participants completed surveys at the beginning of the program. The surveys measured self-reported physical activity, as well as theoretical construct of self-efficacy and those related to the Theory of Planned Behavior-attitude, social norms, perceived behavioral control and intention. Sixty percent of participants were found to meet the program's goals. Self-reported physical activity ( $p=0.036)$, barrier self-efficacy $(p=0.016)$, walking self-efficacy $(\mathrm{p}=0.002)$, and intention $(\mathrm{p}<0.001)$ were greater in those who met the goals than those who did not meet the goals of the program. Walking self-efficacy ( $\mathrm{p}<0.001)$, attitude $(\mathrm{p}<0.001)$ and perceived behavioral control ( $\mathrm{p}$ $=0.024)$ were all found to predict intention to walk and intention was a significant predictor of whether or not the participants met goals of the program $(\mathrm{p}=$ 0.022). This suggests behavioral interventions aimed at increasing participant self-efficacy and intentions could positively affect program adherence and the successfulness of a workplace wellness program.
\end{abstract}

\section{Keywords}

Physical Activity, Theory, Worksite Health, Self-Efficacy, Theory of Planned Behavior

\section{Introduction}

An objective of Healthy People 2020 is to increase the amount of employed 
adults who have access to and take advantage of employer-based exercise facilities and exercise programs [1]. Employer-based wellness programs have recently received an enormous amount of attention not only from Healthy People 2020, but also from the private and government sectors in an effort to increase the health of the populations targeted, but also to serve as a primary prevention strategy [2] [3] [4]. Employers can reap the financial benefits of wellness programs. More than $60 \%$ of Americans receive their health insurance coverage through an employment-based plan [5]. Wellness programs can lead to reduced expenditure on health care [3] [6] [7]. Many employees spend a large majority of their waking hours at the workplace and in a recent study it was found that for every dollar spent on wellness programs medical costs fall by $\$ 3.27$ and absenteeism costs fall by $\$ 2.73$ [3]. Another study found that for every dollar spent there was a $\$ 2.53$ return of investment on workplace health promotion programs [8]. The former U.S. Surgeon General Regina Benjamin urged business executives to understand their role and to commit to changes that promote health and wellness [1]. The percentage of firms offering wellness programs has increased to $65 \%$ in 2011 from $58 \%$ in $2009,14 \%$ of those employers offer incentives like gift cards or cash to increase participation in corporate wellness [9]. These factors reaffirm why the workplace is the most reasonable setting to provide disease prevention and health promotion.

However, the implementation of these workplace health promotion programs warrants the use of best practices to obtain the desired results [10]. The two major threats to employer-based wellness program success involve employee participation and adherence to programs. Further research needs to be performed on effective recruitment and attrition prevention [11]. To properly analyze these factors the research should be based on best practices and theories relevant to health behavior [2]. Self-Efficacy Theory [12] and the Theory of Planned Behavior [13] [14] [15] are two commonly used theories of health behavior that could provide knowledge on the best predictors of participant adherence to workplace interventions.

Self-efficacy is the belief that one can successfully execute the behavior required to produce the outcomes and has consistently presented itself as a determinant of health behavior in adults [12]. Self-efficacy is a commonly studied predictor of physical activity and a mediator of intervention effects on physical activity [16] [17] [18]. Not only are those with higher self-efficacy more likely to perform physical activity, they are also more likely to maintain exercise over a period of time. Self-efficacy may serve as a mediator between intention and behavior change [19] [20].

In workplace interventions, self-efficacy has been found to be strongly associated with physical activity [17]. But, for adults, increasing self-efficacy has shown to be difficult, and interventions at the workplace have been only moderately successful in increasing self-efficacy to promote exercise. Yet, when self-efficacy is successfully improved throughout an intervention, attrition from exercise programs can be reduced [21]. In an intervention to increase walking 
among middle-aged adults, the intervention group walked more frequently, for longer durations, and greater distances [22]. Surprisingly, the intervention had direct effects on adherence rather than through self-efficacy. Self-efficacy was only significantly predictive of walking adherence at early and middle stages, but not during the last month of the program.

The Theory of Planned Behavior is another commonly used theory to predict physical activity behaviors [13]. In this theory, intention is believed to be the most proximal predictor of behavior. The other constructs included in the model are attitude and subjective norms, which predict intention, and perceived behavior control, which is thought to have influence on intention and behavior. Overall, the Theory of Planned Behavior proposes that an individual will intend to engage in a behavior if he or she assigns a positive evaluation to it, believes that significant others think he or she should complete it, and perceives the behavior to be under his or her control [14].

The Theory of Planned Behavior has been applied to the prediction of a plethora of behaviors, including physical activity [23]. In a study of college students engaging in exercise after a two-week follow-up period, intention and perceived behavioral control accounted for $43 \%$ of the variance in exercise behavior [20]. Attitude and perceived behavioral control were successfully predictive of intention. Similarly, a study of participants enrolled in a gym membership found perceived behavioral control was significant predictor of intention and exercise behavior at a 12-week follow-up [24]. Another study by Godin, Valois and Lepage found conflicting results [25]. Perceived behavioral control was not directly related to behavior, but rather it influenced intention. This study suggested that perceived behavioral control was only useful in understanding exercise intention, but not predictive of exercise behavior [25].

Walking as exercise has been highlighted as a free and relatively low-impact form of exercise from which many health benefits can be accrued [26] [27]. A recent meta-analysis found that the benefits from walking include significant decreases in systolic and diastolic blood pressure, resting heart rate, body fat, BMI, total cholesterol, 6-minute walk time and depression, while increases were seen in $\mathrm{VO}_{2}$ max and quality of life for physical functioning. These were improvements were found despite about $75 \%$ of the participants were active at a level below moderate physical activity guidelines [28]. This demonstrates that even a minimal change in walking behavior can still have a significant impact on health. These findings are similarly to other studies that have found walking to improve all-cause mortality, body composition and body composition [29] [30]. Similarly, a recent scoping review found that walking improved mental health [31]. Pedometer-based walking programs can result in moderate weight loss, with the longer the program the higher the weight loss [32]. A systematic review of pedometer-programs assessed that pedometers increased the mean steps by 2491 steps per day [33].

Numerous studies have evaluated the effectiveness and efficiency of interven- 
tions to promote exercise and physical activity, and commonly the studies rely on the constructs of Self-efficacy theory and Theory of Planned Behavior, but few have used these theories to predict adherence to a walking program in corporate wellness setting [34] [35]. The purpose of this study was to use theoretical constructs to predict walking behavior in a pedometer-based, corporate wellness program.

\section{Methods}

\subsection{Participants}

Participants were recruited from a private university in the Southeastern part of the United States in September 2015. All participants had at that time agreed to participate in a pedometer-based walking program put on by the university's wellness program. After they had signed up for the program, the authors contacted all the participants in the program to see if they would be willing to participate in a study about the effectiveness of the walking program. The original sample consisted of 110 faculty and staff who were enrolled in the walking program through the university's wellness center and agreed to participate in the study. There were $93(84.5 \%$ ) females (mean age $=42.0 \pm 11.6$ years; BMI $=27.2$ $\pm 6.0 \mathrm{~kg} / \mathrm{m}^{2}$ ). Additionally, $88.2 \%$ of the participants classified themselves as white and $89.2 \%$ had at least a college degree (see Table 1 for additional details about the sample). The research protocol was approved by the Institutional Review Board and all participants gave informed consent to participate in the study. Participants who completed the study were given a $\$ 10$ gift card from the authors.

\subsection{Measures}

Physical Activity: The Godin Leisure-Time Exercise Questionnaire was used to assess physical activity habits over a 7-day period [36]. It asks how often individuals engage in light, moderate, and strenuous activities for at least 15 minutes or more. They were asked which exercises they typically do throughout the week

Table 1. Demographic characteristics of sample.

\begin{tabular}{cc}
\hline Characteristic & Frequen and Percentage \\
White $(\mathrm{n}=97 ; 88.2 \%)$ \\
Ethnicity \\
Black or African American $(\mathrm{n}=6 ; 5.5 \%)$ \\
Hispanic/Latino $(\mathrm{n}=2 ; 1.8 \%)$ \\
Asian American $(\mathrm{n}=1 ; 0.9 \%)$ \\
Did not answer $(\mathrm{n}=4 ; 3.6 \%)$ \\
High School Graduate/Some College $(\mathrm{n}=13 ; 11.8 \%)$ \\
College Degree/Some Grad School $(\mathrm{n}=38 ; 36.4 \%)$ \\
Graduate Degree $(\mathrm{n}=57 ; 51.8 \%)$ \\
Normal weight (BMI $18.5-24.99 ; \mathrm{n}=42)$ \\
Overweight (BMI $25.0-29.99 ; \mathrm{n}=34)$ \\
Obese (BMI 30.0 and greater; $\mathrm{n}=28)$ \\
Body Mass Index
\end{tabular}


with three items divided into strenuous (heart beats rapidly), moderate (not exhausting), and mild (minimal effort). Those items were measured on an 8-point scale from (0) "none" to (8) "8 or more times a week".

Barrier Self-Efficacy: The Barriers Specific Self-Efficacy Scale was used to gauge subjects' perceived capabilities to walk 5 miles a day for the next 9 weeks in the face of commonly identified barriers to participation [37]. Barrier Self-Efficacy was measured by 13 items such as boredom, poor weather, and pain. For each item, participants were instructed to indicate their confidence to adhere to walking on a 100-point percentage scale composed of 10-point increments, ranging from $0 \%$ "not at all confident" to $100 \%$ "highly confident". The mean score of this scale was used to determine barriers self-efficacy. This scale has been used extensively in the literature and has been used in research evaluating walking programs in adults [38] [39].

Walking Self-Efficacy: Walking self-efficacy was assessed based on the principles set forth by Bandura [12] to measure the level and strength of the behavior. This scale measured an individual's beliefs in their ability to continue walking 5 miles a day in the future. There were 9 items from "I am able to continue walking 5 miles per day for the next week" to "week nine". For each item, participants were instructed to indicate their confidence to adhere to walking on a 100-point percentage scale composed of 10-point increments, ranging from $0 \%$ "not at all confident" to $100 \%$ "highly confident". The mean score of this scale was used to determine barriers self-efficacy. This scale has been found to be a valid and reliable measure of self-efficacy [39] [40].

Theory of Planned Behavior. The Theory of Planned Behavior Questionnaire was used to assess each of the Theory of Planned Behavior's main constructs: perceived behavioral control, attitude, intention, and subjective norm [15]. The items were designed to be compatible with the behavioral criterion and to be self-directed based on the goal of walking 5 miles per day [29]. The specific measurement of each of the constructs of the Theory of Planned Behavior is discussed below. The sum of the items for the different constructs was used.

Perceived Behavioral Control: Items for perceived behavioral control measured a participant's perceived ease or difficulty assigned to walking. Four items measured this such as, "For me to walk 5 miles a day on a regular basis is ... 1 (extremely difficult) to 7 (extremely easy)."

Attitude: Items for attitude measured the positive or negative evaluation of walking. Five items measured this such as, "For me to walk 5 miles a day on a regular basis is ... 1 (extremely good) to 7 (extremely bad)."

Subjective Norm: Items for subjective norm measured the participant's potential perceived social pressures to perform or not to perform the particular behavior. Three items measured this such as, "Most of my colleagues in this program with whom I am acquainted with walk 5 miles a day on a regular basis ... 1 (definitely true) to 7 (definitely false)."

Intention: Items for intention measured the intent to walk 5 miles on a daily 
basis. Three items measured this such as, "I plan to walk 5 miles a day on a regular basis ... 1 (extremely likely) to 7 (extremely unlikely)."

\subsection{Procedures}

Participants were recruited from a pedometer-based, corporate wellness walking program aimed to increase participants' amount of daily walking. This was a pre-existing program that was being sponsored by our university's wellness program. The overall goal of this program was to walk 225 miles over a 9-week period ( 5 miles a day for 5 days per week; an assumption of the program was that 10,000 steps was equivalent to 5 miles). It is important to note that the 9 weeks were during the fall season in the southeast of the US so the weather was relatively mild. Upon registration, participants were given a pedometer and asked to $\log$ their daily step count and electronically submit it each night. At the conclusion of the 9 weeks, if the participants walked at least 225 miles they were entered in a grand prize drawing by the program sponsors and the participants who met this goal were classified as adhering to the program goals.

During the first week of the program, those who chose to participate in the walking program were asked to participate in this study by completing surveys through a website. The participants' survey answers were analyzed alongside how many miles each participant walked during the program to determine which factors were most effective in predicting adherence to the walking program.

\subsection{Data Analysis}

All statistical analyses were conducted using IBM SPSS, Version 23.0. Significance was set a priori at an alpha level of $<0.05$. ANOVAs were initially performed to determine if demographic variables influenced the were run to determine if there were significant differences in demographic and theoretical constructs in those who met the goals of the program and those who did not meet.

A logistic regression equation was performed to determine which variables would successfully predict adherence to the walking program-225 miles over 9-week program. For this logistic regression, age, BMI and physical activity at baseline were entered as a first step. In the second step, all theoretical constructs from Theory of Planned Behavior and Self-Efficacy Theory were entered.

Additionally, a multiple linear regression analysis was performed to determine the impact of theoretical constructs on intention to perform physical activity. Once again, step 1 included age, BMI and self-reported physical activity and step two were all remaining theoretical constructs.

\section{Results}

Of the 110 participants who completed the baseline measures, 102 actually participated in the program by logging number of miles walked throughout the program. Of these 102 participants, $60 \%$ of participants met the program's goals of 
walking 225 miles over 9 weeks. Self-reported physical activity $(\mathrm{p}=0.036)$, barrier self-efficacy $(\mathrm{p}=0.016)$, walking self-efficacy $(\mathrm{p}=0.002)$, and intention $(\mathrm{p}=$ 0.001 ) were greater at baseline in those who met the goals than those who did not meet the goals of the program (see Table 2). There were no differences for attitude ( $p=0.090)$, subjective norms, perceived behavioral control, BMI or age $(\mathrm{p}>0.10)$. All Cronbach $\alpha$ coefficients can be found in Table 2. All scales were deemed acceptable except for the social norms scale which had an $\alpha$ coefficient $=$ 0.410 .

Results of the binary logistic regression showed a significant association at Step $1\left(\chi^{2}(3)=9.11, \mathrm{p}=0.028\right)$ which was attributable to physical activity $(\mathrm{p}=$ 0.017), being a significant predictor for meeting the program goals (see Table 3 ). However, in Step 2 when entering the theoretical constructs the variables at that step was significant $\left(\chi^{2}(6)=15.41, \mathrm{p}=0.017\right)$ with intention being the only significant predictor $(\mathrm{p}=0.022)$ of whether participants met the goals of the program. The overall model had a $\chi^{2}(9)=24.52, p=0.004$. See Table 3 for additional information concerning the logistic regression.

A multiple linear regression analysis was then performed to determine the theoretical constructs that were predictive of intention. The first step was not statistically significant $\left(F(3,96)=2.623, \mathrm{p}=0.055, R^{2}=0.08\right)$, see Table 4 . However, when the other theoretical constructs were theoretical constructs were included in the regression there was a significant effect $(F(5,91)=26.62, \mathrm{p}<$ $0.001, R^{2}$ change $\left.=0.55\right)$. This was due to walking self-efficacy $(\mathrm{p}<0.001)$, attitude $(\mathrm{p}<0.001)$ and perceived behavioral control $(\mathrm{p}=0.024)$ all being significant predictors of intention. See Table 4 for a complete description of the regression analysis.

\section{Discussion}

The purpose of this study was to examine if theoretical constructs from

Table 2. Means $( \pm S D)$ of demographic and theoretical constructs for those who met their goals and those who did not meet goals.

\begin{tabular}{ccccc}
\hline & Met goals & Did not meet goals & $\alpha$ & $\mathrm{p}$ \\
\hline $\mathrm{n}$ & 61 & 41 & & \\
Age & $42.6 \pm 11.9$ & $40.5 \pm 11.1$ & & 0.358 \\
BMI & $26.9 \pm 5.5$ & $28.0 \pm 6.6$ & & 0.391 \\
Physical Activity (Godin)* & $34.4 \pm 23.2$ & $25.5 \pm 16.7$ & & 0.036 \\
Walking Self-Efficacy & $72.3 \pm 27.2$ & $56.3 \pm 22.1$ & 0.986 & 0.002 \\
Barrier Self-Efficacy & $54.1 \pm 18.6$ & $44.5 \pm 19.2$ & 0.900 & 0.016 \\
Attitude & $30.0 \pm 4.3$ & $28.6 \pm 4.4$ & 0.777 & 0.090 \\
Subjective Norm & $14.1 \pm 4.0$ & $13.8 \pm 2.9$ & 0.410 & 0.642 \\
Perceived Behavior Control & $21.6 \pm 5.1$ & $20.2 \pm 4.8$ & 0.792 & 0.186 \\
Intention & $18 * *$ & $15.7 \pm 3.8$ & 0.844 & $<0.001$ \\
\hline
\end{tabular}


Table 3. Logistic regression to predict whether participant met goals of the program.

\begin{tabular}{|c|c|c|c|c|c|}
\hline & B & SE B & Wald $\chi^{2}$ & $\mathrm{p}$ & OR \\
\hline \multicolumn{6}{|l|}{ Step 1} \\
\hline BMI & -0.018 & 0.037 & 0.235 & 0.628 & 0.982 \\
\hline Age & 0.037 & 0.021 & 3.260 & 0.071 & 1.038 \\
\hline Physical activity & 0.031 & 0.013 & 5.742 & 0.017 & 1.032 \\
\hline Model $\chi^{2}=9.12, p=0.028$ & \multicolumn{5}{|c|}{ Pseudo $R^{2}=0.13$} \\
\hline \multicolumn{6}{|l|}{ Step 2} \\
\hline BMI & -0.021 & 0.042 & 0.261 & 0.610 & 0.979 \\
\hline Age & 0.042 & 0.023 & 3.487 & 0.062 & 1.043 \\
\hline Physical activity & 0.027 & 0.016 & 2.784 & 0.095 & 1.027 \\
\hline Walking Self-efficacy & 0.019 & 0.017 & 1.248 & 0.264 & 1.019 \\
\hline Barrier Self-efficacy & 0.006 & 0.018 & 0.126 & 0.723 & 1.006 \\
\hline Attitude & -0.038 & 0.072 & 0.283 & 0.595 & 0.962 \\
\hline Social Norm & -0.022 & 0.089 & 0.063 & 0.801 & 0.978 \\
\hline Perceived behavior control & -0.151 & 0.086 & 3.068 & 0.080 & 0.860 \\
\hline Intention & 0.294 & 0.129 & 5.224 & 0.022 & 1.342 \\
\hline Model $\chi^{2}=24.52, \mathrm{p}=0.004$ & \multicolumn{5}{|c|}{ Pseudo $R^{2}=0.31 ; R^{2}$ change $=0.18$} \\
\hline
\end{tabular}

Table 4. Prediction of intention to walking program.

\begin{tabular}{ccccccc}
\hline & $\mathrm{B}$ & $\mathrm{p}^{\#}$ & $R$ & $R_{\text {change }}^{2}$ & $F_{\text {change }}$ & $\mathrm{p}^{\mathrm{t}}$ \\
\hline Step 1 & & & & & & \\
BMI & -0.088 & 0.383 & & & & \\
Age & -0.032 & 0.757 & & & & \\
Physical activity & 0.234 & 0.027 & 0.275 & 0.08 & 2.62 & 0.055 \\
Step 2 & & & & & & \\
BMI & 0.003 & 0.967 & & & & \\
Age & 0.004 & 0.951 & & & & \\
Physical activity & -0.104 & 0.197 & & & & \\
Walking Self-efficacy & 0.474 & $<0.001$ & & & & \\
Barrier Self-efficacy & -0.006 & 0.946 & & & & \\
Attitude & 0.270 & $<0.001$ & & & & \\
Social Norm & 0.071 & 0.370 & & & & \\
Perceived behavior control & 0.234 & 0.024 & 0.790 & 0.55 & & \\
\hline
\end{tabular}

Self-Efficacy Theory [12] and the Theory of Planned Behavior [13] [14] could be utilized to predict adherence to a 9-week corporate wellness walking program. Of the 102 participants who participated and completed the program, 60\% of the participants successfully reached the program goal of 225 miles over the time of 
the program. Initial analyses found that at the beginning of the program, those who successfully completed the program had greater walking and barriers self-efficacy as well as intention to complete the walking program. The results of the logistic regression demonstrated that intention was the only significant predictor of whether or not participants completed the goal of the walking program. The results of the current study supports a majority of studies on physical activity behavior which suggests that intention is a strong predictor of such behavior based on the Theory of Planned Behavior [20] [23] [25] [34] [41] [42]. A recent study of walking behavior found the Theory of Planned Behavior to be a useful theory to predict behavior and for future interventions [43]. Therefore, interventions that could change a participant's intentions would be beneficial to increase physical activity behavior and adherence to exercise programs. In order to bolster one's intention to exercise, interventions may focus on showing the benefits of physical activity and how to overcome the obstacles. Also, timeliness is important in that interventions should focus on immediate behavior to help bridge the intention-behavior gap that is often problematic in exercise and other health interventions [19] [44] [45].

In the current study, it was also found that attitude, perceived behavioral control and walking self-efficacy were significant predictors of intention, but they did not have a direct effect on walking behavior in this wellness program. This is consistent with previous research which has found constructs of Theory of Planned Behavior predicted intention, but not exercise behavior [46]. The finding in the current study that attitude and perceived behavioral control were significant predictors with intention to walk is similar to previous findings for walking and other physical activity [25] [41] [42], but contrary to one study on walking behavior that found attitude had no association with intention [34]. In order to improve attitude one would need to provide participants with enjoyable physical activities which allow them to have a positive evaluation of physical activity. Walking programs are an ideal intervention to initiate physical activity because most people will experience positive affect from acute bouts of walking [47] which likely influence attitudes to future exercise and exercise adherence [48].

The fact that perceived behavioral control predicted intention, but not adherence to the walking program in the present study is consistent with other previous studies [25] [41], but contrary to other findings which suggest perceived behavioral control to be directly related to exercise behavior [20] [24] [42]. The usefulness of perceived behavioral control on exercise behavior is often debated and some would suggest perceived behavioral control and self-efficacy are similar constructs, so not surprising that both were predictors of exercise intention in the current study. However, in an effort to increase perceived behavioral control to increase intention to exercise, practitioners should help those participating in the program develop skills to help overcome barriers such as time [18]. Understanding the barriers that they experience or perceive would be helpful in overcoming these barriers and increase perceived behavioral control. 
In previous research, self-efficacy, similar to perceived behavioral control, has been shown in as a mediator and a predictive factor that increases intention to exercise [18] [19]. Although previous studies have also shown exercise self-efficacy to be the best predictor of physical activity and the most significant predictor of adherence to exercise [40] [49] [50]. Surprisingly, in the current study walking self-efficacy was not a significant predictor of adherence, but did influence intention to exercise. In an effort to improve self-efficacy, it is known that a primary source of self-efficacy is past performance accomplishments [12]. Due to the low intensity of walking programs, it should be relatively easy for practitioners to progressively increase the volume of these programs and increase self-efficacy to complete. Another good source of self-efficacy is vicarious experiences [12]; therefore, providing group based programs could also be beneficial to increase self-efficacy and adherence to physical activity programs.

Barrier self-efficacy was not a significant predictor of intention or adherence to the walking program, which is inconsistent with previous research which has found barrier self-efficacy to be important in exercise behavior [37] [51] [52] [53]. In this study, participants' belief in their ability to walk was more significant on intention than their belief to overcome barriers to walking. Additionally, subjective norm did not predict intention or adherence to the walking program in the current study. This may have been due to issues around measurement of this construct as can be seen by the low alpha coefficients for this variable. The inability of subjective norm to predict walking behavior is consistent with previous research [41] [42].

A limitation of the study may have been the electronic reporting of daily walking and physical activity. Some participants may have felt overwhelmed by the need to report each day, which may have led to attrition from the program or results may have been less than accurate because of missed days of reporting. However, participants were offered various incentives throughout the program which hopefully limited this non-reporting behavior. Another limitation comes from the sample that we were able to obtain. Our sample size was modest in size, primarily female and fairly well educated which may make it hard to generalize the findings. However, this population is likely indicative of many corporate health promotion programs and all efforts were made to recruit as many participants as possible from those participating in the walking program. Additionally, in the current study it was not known whether the participant's goals were the same or similar to the program goals. A recent systematic review suggests that physical activity interventions should consider integration of various goals on motivation to do physical activity [54]. A final limitation comes from the measurement of the subjective norm variable in the Theory of Planned Behavior which had a low alpha coefficient and may not be a strong predictor of physical activity behavior [42].

Future studies and interventions may want to tailor materials to make the intervention more effective. Physical activity interventions at the workplace found 
that tailoring materials to an individual's stage of motivational readiness was positively correlated to an increase in self-reported exercise behavior [55]. Those receiving printed materials that related to their level of readiness, such as self-efficacy, self-reported (37\% vs. $27 \%$ ) increases in their exercise behavior as compared to those receiving generic exercise promotion materials [55]. When promoting walking, tailoring interventions to individuals' levels, such as the most motivated or most sedentary, resulted in the greatest ability to encourage walking [56].

Additionally, future physical activity interventions could consider the inclusion of media or social media campaigns to help strengthen theoretical constructs such as self-efficacy, perceived behavioral control and attitude. Previous studies have found media campaign messages based on constructs from the Theory of Planned Behavior to be effective in increasing walking behavior [57] [58] [59].

\section{Conclusion}

In conclusion, the current study examined theoretical constructs from Self-Efficacy Theory [12] and the Theory of Planned Behavior [13] [14] [15] to better understand adherence to a walking program implemented by a university's wellness center. This study found that the only significant predictor of adherence to the walking program was intention. Attitude, perceived behavioral control and walking self-efficacy were significant predictors of intention. Some ways to intervene to improve physical activity behavior and adherence are discussed in relation to these theoretical constructs used in the current study.

\section{Conflicts of Interest}

The authors declare no conflicts of interest regarding the publication of this paper.

\section{References}

[1] Office of Disease Prevention and Health Promotion (2017) Physical Activity | Healthy People 2020.

https://www.healthypeople.gov/2020/topics-objectives/topic/physical-activity/object ives

[2] Cahalin, L.P., Kaminsky, L., Lavie, C.J., et al. (2015) Development and Implementation of Worksite Health and Wellness Programs: A Focus on Non-Communicable Disease. Progress in Cardiovascular Diseases, 58, 94-101. https://doi.org/10.1016/j.pcad.2015.04.001

[3] Baicker, K., Cutler, D. and Song, Z. (2010) Workplace Wellness Programs Can Generate Savings. Health Affairs, 29, 304-311.

https://doi.org/10.1377/hlthaff.2009.0626

[4] Steinbrook, R. (2009) Health Care and the American Recovery and Reinvestment Act. New England Journal of Medicine, 360, 1057-1060. https://doi.org/10.1056/NEJMp0900665

[5] Blumenthal, D. (2006) Employer-Sponsored Health Insurance in the United States-Origins and Implications. New England Journal of Medicine, 355, 82-88. 
https://doi.org/10.1056/NEJMhpr060703

[6] Berry, L.L., Mirabito, A.M. and Baun, W.B. (2010) What's the Hard Return on Employee Wellness Programs? Harvard Business Review, 88, 104-112, 142.

[7] Zivin, K., Sen, A., Plegue, M.A., et al. (2017) Comparative Effectiveness of Wellness Programs: Impact of Incentives on Healthcare Costs for Obese Enrollees. American Journal of Preventive Medicine, 252, 347-352. https://doi.org/10.1016/j.amepre.2016.10.006

[8] Dement, J.M., Epling, C., Joyner, J. and Cavanaugh, K. (2015) Impacts of Workplace Health Promotion and Wellness Programs on Health Care Utilization and Costs: Results from an Academic Workplace. Journal of Occupational and Environmental Medicine, 57, 1159. https://doi.org/10.1097/JOM.0000000000000555

[9] Klautzer, L., Mattke, S. and Greenberg, M. (2012) Can We Legally Pay People for Being Good? A Review of Current Federal and State Law on Wellness Program Incentives. International Journal of Health Care Finance and Economics, 49, 268-277.

[10] Goetzel, R.Z., Henke, R.M., Tabrizi, M., et al. (2014) Do Workplace Health Promotion (Wellness) Programs Work? Journal of Occupational and Environmental Medicine, 56, 927. https://doi.org/10.1097/JOM.0000000000000276

[11] Marshall, A.L. (2004) Challenges and Opportunities for Promoting Physical Activity in the Workplace. Journal of Science and Medicine in Sport, 7, 60-66. https://doi.org/10.1016/S1440-2440(04)80279-2

[12] Bandura, A. (1977) Self-Efficacy: Toward a Unifying Theory of Behavioral Change. Psychological Review, 84, 191-215. https://doi.org/10.1037/0033-295X.84.2.191

[13] Ajzen, I. (1985) From Intentions to Actions: A Theory of Planned Behavior. In: Action Control, SSSP Springer Series in Social Psychology, Springer, Berlin, Heidelberg, 11-39. https://doi.org/10.1007/978-3-642-69746-3_2

[14] Ajzen, I. (2005) Attitudes, Personality, and Behavior. 2nd Edition, McGraw-Hill Education, UK.

[15] Fishbein, M. and Ajzen, I. (2011) Predicting and Changing Behavior: The Reasoned Action Approach. Psychology Press, New York. https://doi.org/10.4324/9780203838020

[16] Dishman, R.K., Motl, R.W., Saunders, R., et al. (2004) Self-Efficacy Partially Mediates the Effect of a School-Based Physical-Activity Intervention among Adolescent Girls. Preventive Medicine, 38, 628-636. https://doi.org/10.1016/j.ypmed.2003.12.007

[17] Prodaniuk, T.R., Plotnikoff, R.C., Spence, J.C. and Wilson, P.M. (2004) The Influence of Self-Efficacy and Outcome Expectations on the Relationship between Perceived Environment and Physical Activity in the Workplace. International Journal of Behavioral Nutrition and Physical Activity, 1, 7. https://doi.org/10.1186/1479-5868-1-7

[18] Stutts, W.C. (2002) Physical Activity Determinants in Adults. Perceived Benefits, Barriers, and Self Efficacy. AAOHN Journal: Official Journal of the American Association of Occupational Health Nurses, 50, 499-507.

[19] Sniehotta, F.F., Scholz, U. and Schwarzer, R. (2005) Bridging the Intention-Behaviour Gap: Planning, Self-Efficacy, and Action Control in the Adoption and Maintenance of Physical Exercise. Psychology \& Health, 20, 143-160. https://doi.org/10.1080/08870440512331317670

[20] Norman, P. and Conner, M. (2005) The Theory of Planned Behavior and Exercise: Evidence for the Mediating and Moderating Roles of Planning on Inten- 
tion-Behavior Relationships. Journal of Sport and Exercise Psychology, 27, 488-504. https://doi.org/10.1123/jsep.27.4.488

[21] McAuley, E., Jerome, G.J., Marquez, D.X., Elavsky, S. and Blissmer, B. (2003) Exercise Self-Efficacy in Older Adults: Social, Affective, and Behavioral Influences. Annals of Behavioral Medicine, 25, 1-7. https://doi.org/10.1207/S15324796ABM2501_01

[22] McAuley, E., Courneya, K.S., Rudolph, D.L. and Lox, C.L. (1994) Enhancing Exercise Adherence in Middle-Aged Males and Females. Preventive Medicine, 23, 498-506. https://doi.org/10.1006/pmed.1994.1068

[23] Prapavessis, H., Gaston, A. and DeJesus, S. (2015) Theory of Planned Behavior as a Model for Understanding Sedentary Behavior. Psychology of Sport and Exercise, 19, 23-32. https://doi.org/10.1016/j.psychsport.2015.02.001

[24] Armitage, C.J. (2005) Can the Theory of Planned Behavior Predict the Maintenance of Physical Activity? Health Psychology, 24, 235-245. https://doi.org/10.1037/0278-6133.24.3.235

[25] Godin, G., Valois, P. and Lepage, L. (1993) The Pattern of Influence of Perceived Behavioral Control upon Exercising Behavior: An Application of Ajzen's Theory of Planned Behavior. Journal of Behavioral Medicine, 16, 81-102.

https://doi.org/10.1007/BF00844756

[26] Lee, I.-M. and Buchner, D.M. (2008) The Importance of Walking to Public Health. Medicine \& Science in Sports \& Exercise, 40, S512-S518.

https://doi.org/10.1249/MSS.0b013e31817c65d0

[27] Korownyk, C. and Allan, G.M. (2010) Motivating Patients to Activity: A Light at the End of the Couch? Canadian Family Physician, 56, 887.

[28] Hanson, S. and Jones, A. (2015) Is There Evidence That Walking Groups Have Health Benefits? A Systematic Review and Meta-Analysis. British Journal of Sports Medicine, 49, 710-715. https://doi.org/10.1136/bjsports-2014-094157

[29] Foulds, H.J.A., Bredin, S.S.D., Charlesworth, S.A., Ivey, A.C. and Warburton, D.E.R. (2014) Exercise Volume and Intensity: A Dose-Response Relationship with Health Benefits. European Journal of Applied Physiology, 114, 1563-1571.

https://doi.org/10.1007/s00421-014-2887-9

[30] Kelly, P., Kahlmeier, S., Götschi, T., et al. (2014) Systematic Review and Meta-Analysis of Reduction in All-Cause Mortality from Walking and Cycling and Shape of Dose Response Relationship. International Journal of Behavioral Nutrition and Physical Activity, 11, 132. https://doi.org/10.1186/s12966-014-0132-x

[31] Kelly, P., Williamson, C., Niven, A.G., Hunter, R., Mutrie, N. and Richards, J. (2018) Walking on Sunshine: Scoping Review of the Evidence for Walking and Mental Health. British Journal of Sports Medicine, 52, 800-806. https://doi.org/10.1136/bjsports-2017-098827

[32] Richardson, C.R., Newton, T.L., Abraham, J.J., Sen, A., Jimbo, M. and Swartz, A.M. (2008) A Meta-Analysis of Pedometer-Based Walking Interventions and Weight Loss. The Annals of Family Medicine, 6, 69-77. https://doi.org/10.1370/afm.761

[33] Bravata, D.M., Smith-Spangler, C., Sundaram, V., et al. (2007) Using Pedometers to Increase Physical Activity and Improve Health: A Systematic Review. JAMA, 298, 2296-2304. https://doi.org/10.1001/jama.298.19.2296

[34] Eves, F., Hoppéa, R. and McLaren, L. (2003) Prediction of Specific Types of Physical Activity Using the Theory of Planned Behavior. Journal of Applied Biobehavioral Research, 8, 77-95. https://doi.org/10.1111/j.1751-9861.2003.tb00086.x 
[35] Ogilvie, D., Foster, C.E., Rothnie, H., et al. (2007) Interventions to Promote Walking: Systematic Review. BMJ, 334, 1204. https://doi.org/10.1136/bmj.39198.722720.BE

[36] Godin, G. and Shephard, R.J. (1985) A Simple Method to Assess Exercise Behavior in the Community. Canadian Journal of Applied Sport Sciences, 10, 141-146.

[37] McAuley, E. (1992) The Role of Efficacy Cognitions in the Prediction of Exercise Behavior in Middle-Aged Adults. Journal of Behavioral Medicine, 15, 65-88. https://doi.org/10.1007/BF00848378

[38] Monroe, C.M., Bassett Jr., D.R., Fitzhugh, E.C., Raynor, H.A. and Thompson, D.L. (2017) Effect of Adding Online Social Support Tools to an Adult Walking Program: A Pilot Randomized Controlled Trial. Health Promotion Practice, 18, 84-92. https://doi.org/10.1177/1524839915626674

[39] Olson, E.A. and McAuley, E. (2015) Impact of a Brief Intervention on Self-Regulation, Self-Efficacy and Physical Activity in Older Adults with Type 2 Diabetes. Journal of Behavioral Medicine, 38, 886-898.

https://doi.org/10.1007/s10865-015-9660-3

[40] McAuley, E. (1993) Self-Efficacy and the Maintenance of Exercise Participation in Older Adults. Journal of Behavioral Medicine, 16, 103-113. https://doi.org/10.1007/BF00844757

[41] Rhodes, R.E., Courneya, K.S., Blanchard, C.M. and Plotnikoff, R.C. (2007) Prediction of Leisure-Time Walking: An Integration of Social Cognitive, Perceived Environmental, and Personality Factors. International Journal of Behavioral Nutrition and Physical Activity, 4, 51. https://doi.org/10.1186/1479-5868-4-51

[42] Symons Downs, D. and Hausenblas, H.A. (2005) The Theories of Reasoned Action and Planned Behavior Applied to Exercise: A Meta-Analytic Update. Journal of Physical Activity \& Health, 2, 76-97. https://doi.org/10.1123/jpah.2.1.76

[43] Sun, G., Acheampong, R.A., Lin, H. and Pun, V.C. (2015) Understanding Walking Behavior among University Students Using Theory of Planned Behavior. International Journal of Environmental Research and Public Health, 12, 13794-13806. https://doi.org/10.3390/ijerph121113794

[44] Rhodes, R.E. and de Bruijn, G.-J. (2013) How Big Is the Physical Activity Intention-Behaviour Gap? A Meta-Analysis Using the Action Control Framework. British Journal of Health Psychology, 18, 296-309. https://doi.org/10.1111/bjhp.12032

[45] Rhodes, R.E. and de Bruijn, G.-J. (2013) What Predicts Intention-Behavior Discordance? A Review of the Action Control Framework. Exercise and Sport Sciences Reviews, 41, 201-207. https://doi.org/10.1097/JES.0b013e3182a4e6ed

[46] Williams, S.L., Michie, S., Dale, J., Stallard, N. and French, D.P. (2015) The Effects of a Brief Intervention to Promote Walking on Theory of Planned Behavior Constructs: A Cluster Randomized Controlled Trial in General Practice. Patient Education and Counseling, 98, 651-659. https://doi.org/10.1016/j.pec.2015.01.010

[47] Ekkekakis, P., Hall, E.E., VanLanduyt, L.M. and Petruzzello, S.J. (2000) Walking in (Affective) Circles: Can Short Walks Enhance Affect? Journal of Behavioral Medicine, 23, 245-275. https://doi.org/10.1023/A:1005558025163

[48] Williams, D.M. (2008) Exercise, Affect, and Adherence: An Integrated Model and a Case for Self-Paced Exercise. Journal of Sport and Exercise Psychology, 30, 471-496. https://doi.org/10.1123/jsep.30.5.471

[49] Lee, L.-L., Avis, M. and Arthur, A. (2007) The Role of Self-Efficacy in Older People's Decisions to Initiate and Maintain Regular Walking as Exercise-Findings 
from a Qualitative Study. Preventive Medicine, 45, 62-65.

https://doi.org/10.1016/j.ypmed.2007.04.011

[50] Marcus, B.H., Selby, V.C., Niaura, R.S. and Rossi, J.S. (1992) Self-Efficacy and the Stages of Exercise Behavior Change. Research Quarterly for Exercise and Sport, 63, 60-66. https://doi.org/10.1080/02701367.1992.10607557

[51] Dawson, J., Hillsdon, M., Boller, I. and Foster, C. (2007) Perceived Barriers to Walking in the Neighborhood Environment: A Survey of Middle-Aged and Older Adults. Journal of Aging and Physical Activity, 15, 318-335. https://doi.org/10.1123/japa.15.3.318

[52] Dunton, G.F. and Schneider, M. (2006) Perceived Barriers to Walking for Physical Activity. Preventing Chronic Disease, 3, A116.

[53] Mailey, E.L., Phillips, S.M., Dlugonski, D. and Conroy, D.E. (2016) Overcoming Barriers to Exercise among Parents: A Social Cognitive Theory Perspective. Journal of Behavioral Medicine, 39, 599-609. https://doi.org/10.1007/s10865-016-9744-8

[54] Rhodes, R.E., Quinlan, A. and Mistry, C.D. (2016) Do Other Goals Influence Physical Activity? A Systematic Review Examining the Relationship between Other Goals and Physical Activity Behavior. Preventive Medicine, 91, 306-317. https://doi.org/10.1016/j.ypmed.2016.08.033

[55] Marcus, B.H., Emmons, K.M., Simkin-Silverman, L.R., et al. (1998) Evaluation of Motivationally Tailored vs. Standard Self-Help Physical Activity Interventions at the Workplace. American Journal of Health Promotion, 12, 246-253. https://doi.org/10.4278/0890-1171-12.4.246

[56] Mackey, M.G., Bohle, P., Taylor, P., Di Biase, T., McLoughlin, C. and Purnell, K. (2011) Walking to Wellness in an Ageing Sedentary University Community: Design, Method and Protocol. Contemporary Clinical Trials, 32, 273-279. https://doi.org/10.1016/j.cct.2010.12.001

[57] Reger-Nash, B., Bauman, A., Cooper, L., et al. (2008) WV Walks: Replication with Expanded Reach. Journal of Physical Activity \& Health, 5, 19-27. https://doi.org/10.1123/jpah.5.1.19

[58] Reger-Nash, B., Fell, P., Spicer, D., et al. (2006) BC Walks: Replication of a Communitywide Physical Activity Campaign. Preventing Chronic Disease, 3, A90. https://www.ncbi.nlm.nih.gov/pmc/articles/PMC1637798/

[59] Reger-Nash, B., Bauman, A., Booth-Butterfield, S., et al. (2005) Wheeling Walks: Evaluation of a Media-Based Community Intervention. Family \& Community Health, 28, 64. https://doi.org/10.1097/00003727-200501000-00009 